\title{
Selection of historic heavy large-scale rainfall events in the Czech Republic
}

\author{
M. $\operatorname{Kaspar}^{1}$ and M. Müller ${ }^{1,2}$ \\ ${ }^{1}$ Institute of Atmospheric Physics AS CR, Prague, Czech Republic \\ ${ }^{2}$ Charles University, Faculty of Science, Prague, Czech Republic
}

Received: 27 June 2008 - Revised: 30 September 2008 - Accepted: 4 November 2008 - Published: 9 December 2008

\begin{abstract}
The Central European floods of July 1997 and August 2002 spotlighted the need for systematic research of the relationships between synoptic-scale conditions and heavy large-scale rainfalls. Creating a set of historic events underlies such research. We defined the criterion for their selection, which is based on daily areal precipitation amounts in predefined sub-regions. To stress the hydrological responses of precipitation, the criterion expresses the temporal distribution of daily areal precipitation in a three-day period. We applied the criterion to clusters of the Czech Republic river basins that were affected by high areal precipitation almost simultaneously during individual events. Finally, we selected events with the ten highest criterion values within each cluster during the warmer half-years from 1951 to 2006.
\end{abstract}

Regarding the spatial extent of heavy rainfalls, we identified a few events during which a substantial part of the Czech Republic was affected. The events include, for instance, the floods of July 1997 and August 2002 that were unique in terms of precipitation totals. The uniqueness of the event in 2002 is that it consisted of two episodes that occurred in rapid succession and demonstrated heavy rainfall that affected almost the same area. Regarding the spatial distribution of precipitation, we identified several groups of events in which heavy rainfall affected similar sub-regions of the Czech Republic. This attribute was most likely related to similar synoptic-scale conditions. In terms of the seasonal variability, the most significant events were concentrated in high summer, which is typical of orographically exposed clusters. Interannual variability of the events was characterized by two main ten-year periods with a rather low frequency of occurrence followed by the years with increased frequency. The analysis of both the hydrological responses and synoptic-dynamic conditions of the events will be the object of further research.

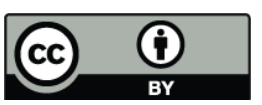

Correspondence to: M. Kaspar (kaspar@ufa.cas.cz)

\section{Introduction}

Flooding is one of the most damaging natural hazards and is a complex hydrological event whose origin and development are influenced by a range of meteorological and nonmeteorological factors. Some of these factors are present for an extended period prior to a flooding event while others only appear immediately before an event (Smith and Ward, 1998). With the exception of a thaw, the primary cause of river flooding in Central Europe is heavy rain. Although the intensity, amounts, and spatial-temporal distribution of precipitation are decisive, the coincidence of the precipitation with specific conditions within river basins is also important. While winter floods are often caused by the combined effect of both heavy rains and the intense melting of snow, the saturation of river basins by antecedent precipitation may play a significant role during the warmer half-year (Brazdil et al., 2005). Two main types of rain floods can, therefore, be distinguished: (i) Flash floods, usually only in the small streams, caused by convective torrential rain and (ii) floods in the major rivers produced by intense long-lasting large-scale rainfalls. The latter type is conditioned by the occurrence of extensive precipitation bands associated with extra-tropical cyclones and/or atmospheric fronts (Matejka et al., 1980). This is the case for the recent Central European floods in July 1997 and August 2002. In 1997, extensive flooding affected mainly the Oder river basin and the tributaries of the Danube (e.g., Kundzewicz et al., 1999; Niedzwiedz, 1999). In 2002, flooding affected the Elbe and Danube river basins (e.g., Grazziny and van der Grijn, 2003; Ulbrich et al., 2003a, b).

After the catastrophic floods of 1997 and 2002, Central European countries have further intensified the research of the relationships between circulation conditions in the synoptic scale and the hydro-meteorological consequences (Mudelsee et al., 2004; Ustrnul and Czekierda, 2001; Wibig, 1999). The common effort of meteorologists is focused on the reduction in the uncertainty of the

Published by Copernicus Publications on behalf of the European Geosciences Union. 
quantitative precipitation forecast (QPF). Primarily, significant large-scale rainfall events are analyzed using regional Numerical Weather Prediction (NWP) models and various ensemble techniques (Zängl, 2004; Sopko, 2003, Keil et al., 1999). In the case of extreme precipitation, the prognostic synoptic-scale fields are generally characterized by smaller uncertainty than the QPF. Therefore, post-processing methods, which are based on conceptual models of causal synoptic weather patterns, are also frequently explored (Porcú et al., 2003; Roberts and Young, 2001; Conway et al., 1996).

The above-mentioned individual research cannot be fully done without an appropriately defined set of historic largescale rainfall events. The events should be selected using a unified methodology that enables researchers to describe and compare them in terms of precipitation totals. There is no exact and unanimously agreed criterion for the selection of the events; however, most researchers select significant events with respect to the highest precipitation totals recorded at individual rain gauge stations (e.g., Martín, et al., 2006; Jansa et al., 2000). Furthermore, this approach is not quite appropriate for the selection of the large-scale and rather nonconvective events because the point-related maxima hardly represent a larger area. Areal precipitation amounts would obviously be a more proper criterion. This fact motivated the initial steps of our research, which are presented in this paper. The first goal is to propose a novel selection criterion that evaluates the extremeness of areal precipitation. We take into account not only precipitation amounts, but also the extent of the affected area and the time concentration of precipitation. Each of these factors plays a significant role in the hydrological response of precipitation in the case of large-scale floods in Central Europe. The application of the criterion enables us to meet the second goal, which is the objective compilation of a set of the most significant events that affected various parts of the Czech Republic (CR). Consequently, the third goal is to describe specific characteristics of the most significant events that have affected the CR in the past from the viewpoint of their spatial extent, simultaneous occurrence, and seasonal, as well as, interannual variability. Due to the limited availability of precipitation data, we considered only the events that occurred in the CR from 1951 to 2006 . We have also restricted the selection to the warmer half-years (May-October) when the precipitation maxima occur in the CR (Tolasz et al., 2007). Indeed, in winter, the hydrological effect of precipitation is often reduced because of the prevailing solid state of precipitation.

\section{Criterion for the selection of large-scale rainfall events}

This section focuses on the main features of a criterion for the selection of the most significant historic large-scale rainfall events that have affected various parts of the CR. The criterion is based on daily areal precipitation amounts in predefined sub-regions of the CR.

\subsection{Areal precipitation amounts in river basins}

Areal precipitation is usually calculated by combining information from rain gauge stations and weather radars (Sokol, 2003). Since high-resolution radar data exist only for the last decade of the period of interest, we utilized only daily precipitation totals measured by rain gauges. Measured daily totals seem to be an acceptable input in the case of non-convective long-lasting rainfalls assuming an adequately dense network of gauges. The accessible gauge network has varied somewhat during the studied period. The number of gauges increased from about 500 in the 1950 s to more than 700 in the 1980 s (i.e., roughly one per $100 \mathrm{~km}^{2}$ ). It is also important to note that the majority of the daily data gaps occurred in the 1950s. More than $50 \%$ of the gauges operated continuously from 1961 onward. The spatial distribution of gauges in the middle of the period of study is shown in Fig. 1. The previously mentioned variability was compensated by a homogenization of the precipitation data set. Missing station data was interpolated from the three nearest correlated gauges using a linear regression. The interpolation was weighed by correlation coefficients among the stations.

Heavy large-scale rainfalls rarely affect the entire Czech territory simultaneously. Therefore, the most significant events should be selected in individual sub-regions separately. In order to stress the hydrological responses of precipitation, these sub-regions should correspond to river basins. The Czech Hydrometeorological Institute (the national weather service) divides the Czech territory into three main catchments of the streams that flow into the North Sea, the Baltic Sea, and the Black Sea. These catchments are further divided into sub-catchments of the second order. We considered 26 of these as basic area units and referred to them as the river basins of the second order. The borders of the river basins of the second order are depicted in Fig. 1.

The standard method of computing areal precipitation was utilized in this study. Daily totals measured by gauges were interpolated into a regular grid. Pure kriging was applied as the gridding method with no orography forcing. This simplification is allowed since our aim is to distinguish the areal precipitation in individual river basins. The areal precipitation in a river basin is then expressed as the mean value calculated from grid points located inside this river basin. It should be noted that the grid points located inside the river basin, but outside the $\mathrm{CR}$, were not included in computations due to the lack of data.

2.2 River basins with simultaneous occurrence of heavy rainfalls

It is evident that areal precipitation amounts differentiate among individual river basins during an event. On the 


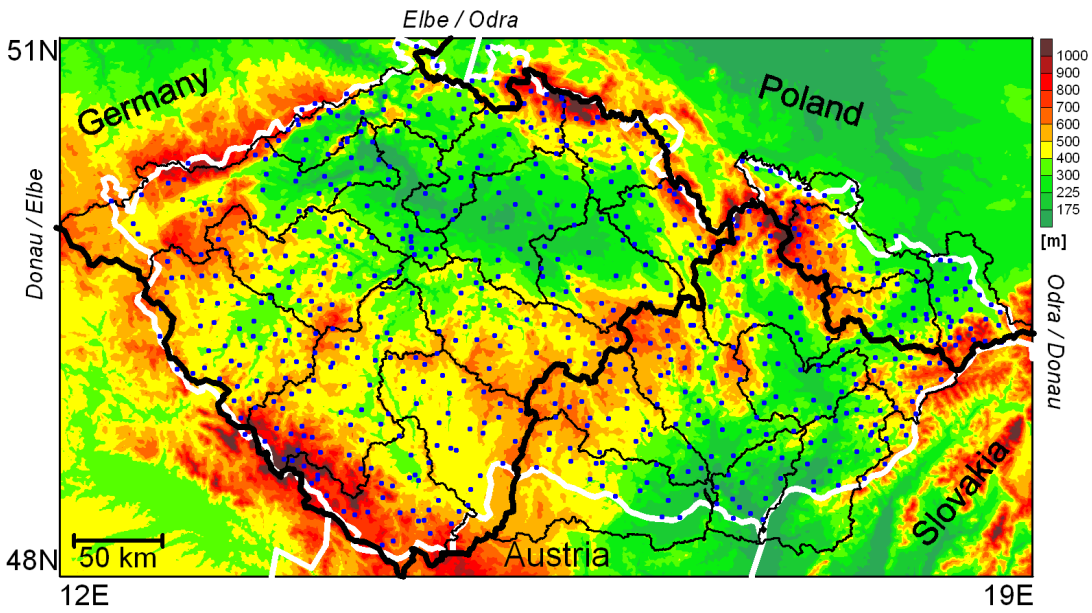

Fig. 1. The hydrological segmentation of the Czech territory into river basins of the second order. The state borders and the watersheds are indicated by white and black lines, respectively. The main European watersheds are highlighted by thick lines. The gauge station network of 1978 is indicated by small blue dots.

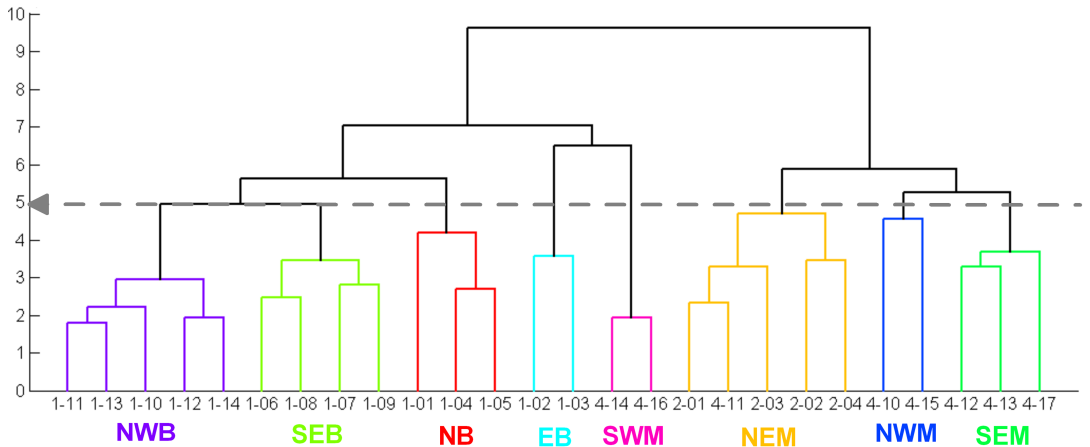

Fig. 2. The dendrogram plot of the hierarchical, binary cluster tree of 26 river basins of the second order. The vertical axis represents the relative measure of the proximity (in $\left[10^{14}\right]$ ) between individual river basins and/or their clusters in terms of normalized areal daily precipitation amounts. The river basins are marked by their indicatives (see Fig. 3) on the horizontal axis. The clusters further used in the study are marked by abbreviations (see Fig. 3 and Table 1). The threshold value of the proximity defining the clusters is indicated by the horizontal dashed arrow.

other hand, heavy large-scale rainfalls nearly always hit areas larger than a river basin. Therefore, we can assume that there are groups of catchments that are affected by high areal precipitation almost simultaneously during individual events. In order to identify such groups, we applied the hierarchical cluster analysis (Campins et al., 2000; Ward, 1963).

Initially, we computed a precipitation threshold given by the percentile 0.99 of the daily areal precipitation in each of the 26 river basins of the second order (Fig. 1). We compiled the set of days in the studied period when daily areal precipitation exceeded the river-basin-related threshold in at least one river basin. Since the parameters of statistical distribution of daily areal precipitation generally differentiate among the river basins, we standardized the values of areal precipitation, $P$, in each river basin by:
$P_{n}=\frac{P-P_{\text {mean }}}{P_{\text {std }}}$

where $P_{n}$ is the standardized value of areal precipitation, $P_{\text {mean }}$ is the mean value of areal precipitation in the studied period and in a given river basin, and $P_{\text {std }}$ is the respective standard deviation. We evaluated the proximity of every pair of basins in terms of standardized daily areal precipitation amounts on selected days using the Minkowski metric (Naber, 1992) and linked the pairs of basins that were in closest proximity. As basins were paired into binary clusters, the newly formed clusters were, by the same manner, grouped into larger clusters until a hierarchical, binary cluster tree was formed. The complete tree is depicted by the dendrogram plot in Fig. 2. The final decision on the proper number of clusters is still an unresolved problem (Gong and Richman, 1995). Our choice was a subjective one based 
Table 1. Description of the river basin clusters defined in Fig. 2.

\begin{tabular}{|c|c|c|c|c|}
\hline Cluster & Location & $\begin{array}{l}\text { Indicatives of } \\
\text { river basins }\end{array}$ & $\begin{array}{l}\text { Area }\left[10^{3} \mathrm{~km}^{2}\right] \\
\text { (inside the CR) }\end{array}$ & Comments \\
\hline NWB & $\begin{array}{l}\text { North-Western } \\
\text { Bohemia }\end{array}$ & $\begin{array}{c}1-10,1-11 \\
1-12,1-13,1-14\end{array}$ & 20 & $\begin{array}{l}\text { Berounka, lower reach of } \\
\text { Vltava, Labe downstream } \\
\text { from the mouth of Vltava } \\
\text { (including Ohre) }\end{array}$ \\
\hline SEB & $\begin{array}{l}\text { South-Eastern } \\
\text { Bohemia }\end{array}$ & $\begin{array}{l}1-06,1-07 \\
1-08,1-09\end{array}$ & 18 & $\begin{array}{l}\text { Vltava as far as the } \\
\text { confluence with Berounka }\end{array}$ \\
\hline NB & Northern Bohemia & $1-01,1-04,1-05$ & 9 & $\begin{array}{l}\text { North-western part of the } \\
\text { Labe catchment as far as } \\
\text { the confluence with Vltava }\end{array}$ \\
\hline $\mathrm{EB}$ & $\begin{array}{l}\text { Eastern } \\
\text { Bohemia }\end{array}$ & $1-02,1-03$ & 5 & $\begin{array}{l}\text { South-eastern part of the } \\
\text { Labe catchment as far as } \\
\text { the confluence with Vltava }\end{array}$ \\
\hline NWM & $\begin{array}{l}\text { North-Western } \\
\text { Moravia }\end{array}$ & $4-10,4-15$ & 8 & $\begin{array}{l}\text { Morava as far as Hana } \\
\text { without Becva, Svratka as } \\
\text { far as Jihlava }\end{array}$ \\
\hline SWM & $\begin{array}{l}\text { South-Western } \\
\text { Moravia }\end{array}$ & $4-14,4-16$ & 6 & $\begin{array}{l}\text { Dyje as far as Svratka, } \\
\text { Jihlava, Svratka from } \\
\text { Jihlava as far as its mouth }\end{array}$ \\
\hline NEM & $\begin{array}{l}\text { North-Eastern } \\
\text { Moravia and Czech } \\
\text { part of Silesia }\end{array}$ & $\begin{array}{c}2-01,2-02, \\
2-03,2-04,4-11\end{array}$ & 8 & $\begin{array}{l}\text { Odra in the Czech part of } \\
\text { Silesia, Becva }\end{array}$ \\
\hline SEM & $\begin{array}{l}\text { South-Eastern } \\
\text { Moravia }\end{array}$ & $4-12,4-13,4-17$ & 6 & $\begin{array}{l}\text { Morava from Hana, lower } \\
\text { reaches of Jihlava, } \\
\text { Svratka and Dyje }\end{array}$ \\
\hline
\end{tabular}

on both meteorological experience and geographic knowledge. Primarily, we took into account the characteristic extent of heavy large-scale rainfalls in the CR. We assessed the threshold value of proximity between every two objects (clusters and/or river basins) and obtained eight clusters of river basins. The clusters are defined in Fig. 2, their locations are depicted in Fig. 3, and the names and description of the clusters are contained in Table 1 . The clusters mostly correspond to the main river basins; however, the cluster NEM in the northeast of the CR consists of river basins from both sides of the main European watershed between Odra and Donau (compare Fig. 1 and 3).

\subsection{Definition of the criterion}

Large-scale rainfall events producing extensive flooding in Czech rivers ordinarily last more than one day - usually two or three days in a river basin (Brazdil et al., 2005). Designing the criterion, we took into account areal precipitation amounts over a period of three days. In addition, the temporal distribution of precipitation during the three-day period should be taken into account. Finally, it should be noted that a higher concentration of precipitation makes the event more dangerous in terms of hydrological responses. Considering

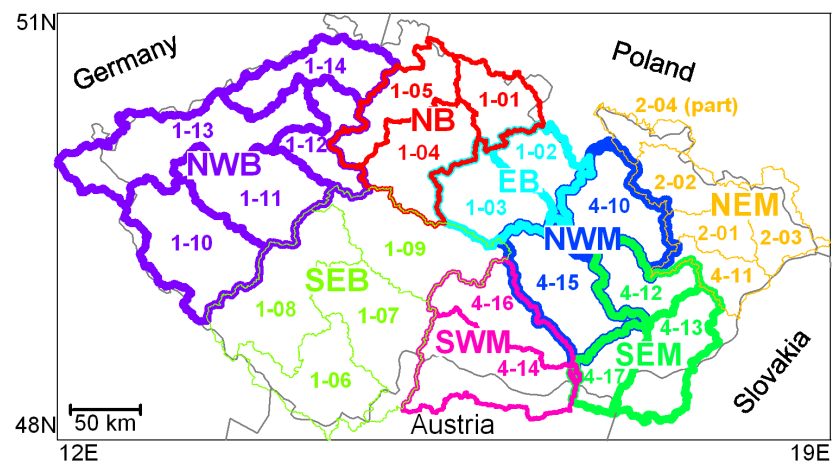

Fig. 3. The location of the river basin clusters defined in Fig. 2. The river basins constituting the individual clusters are marked by their indicatives (see Table 1).

these assumptions, we suggest the following criterion:

$R_{x}=\frac{3 R_{\max }+2 R_{\text {med }}+R_{\text {min }}}{6}$

where $R_{\max }$ is the maximum value of daily areal precipitation, $R_{\text {med }}$ is the second highest value of daily areal precipitation, and $R_{\min }$ is the minimum value of daily areal precipitation in the three-day period. The value of the criterion, 


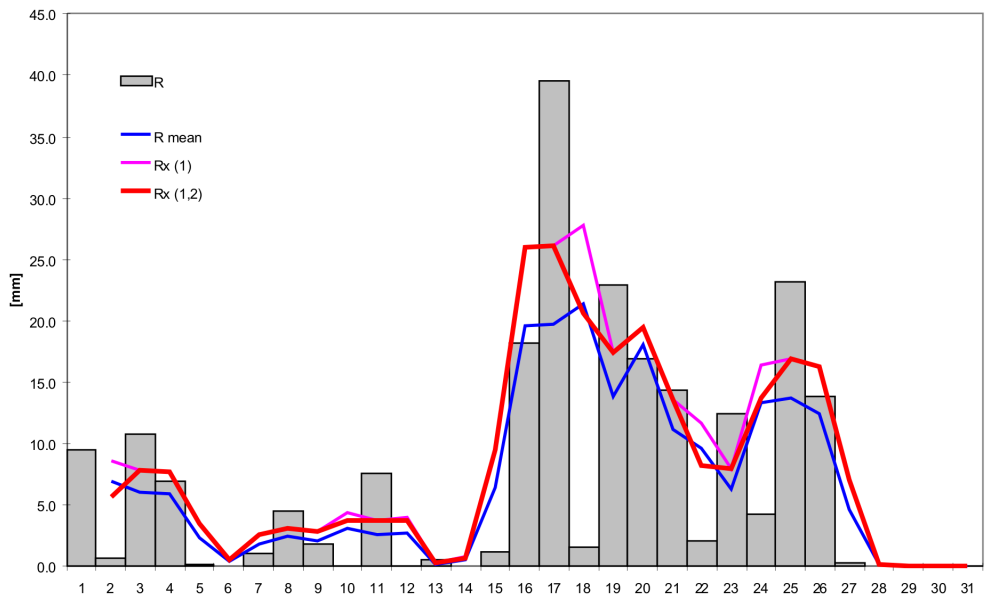

Fig. 4. Example of areal daily precipitation amounts, $R$, in the cluster NEM (see Fig. 3 and Table 1) during July 2001 and the discussed criteria of extremeness of precipitation: mean value of a three-day period $-R_{\text {mean }}$, criterion $R_{x}$ calculated only by the Eq. (2) $-R_{x}(1)$, and final criterion generally calculated by Eq. (2), but by Eq. (3) only when the second day corresponds to the precipitation minimum $-R_{x}(1,2)$. For each three-day period, the values of the criteria are assigned to the second day of the period.

$R_{x}$, is equal to or greater than the mean value of daily areal precipitation in the three-day period. If precipitation is distributed evenly during the period, $R_{x}$ is close to the mean value of daily areal precipitation. On the contrary, if precipitation is concentrated over a shorter period, the value of $R_{x}$ is larger. The comparison between the criterion and the mean is demonstrated in Fig. 4.

However, if the second day of the three-day period has the minimum of precipitation, the hydrological response is significantly reduced due to separation of the runoff into two waves. Moreover, such a period can join the last day and the first day of two independent events as shown in Fig. 4. For this reason, if the second of the three-day period has the minimum precipitation, it is necessary to apply a modified formula:

$R_{x}=\frac{3 R_{\max }+3 R_{\min }}{6}$

In Eq. (3), $R_{\text {med }}$ is substituted by $R_{\min }$ so the final value of $R_{x}$ is reduced for this three-day period. Significant rainfall events correspond then with local maxima of $R_{x}$ in time.

\section{Heavy large-scale rainfall events in warmer half-years 1951-2006}

We evaluated the extremeness of heavy large-scale rainfall events in terms of areal precipitation amounts employing the criterion, $R_{x}$, defined by Eqs. (2) and (3) in Sect. 2.3. First, we applied the criterion to each of the river basins of the second order considering only the warmer half-years from 1951 to 2006. Next, we applied the criterion to the clusters of the river basins. It should be noted that the latter application is legitimate because we are only interested in the most significant events that were accompanied by daily areal precipitation used in defining the clusters. We treat a rainfall event within a cluster as an exceptional precipitation event EPE if the value of the criterion, $R_{x}$, ranks among the five historically highest values of $R_{x}$ in that location. Events with the 6th to the 10th largest values of $R_{x}$ are further called ePE. Thus, the return period of an area-related EPE and ePE is higher than ten and five years, respectively. Considering all of the clusters together, there are 22 EPEs, which are listed in Fig. 5, and there are 20 ePEs. Since some EPEs or ePEs occurred simultaneously in different clusters, their total number is less than the theoretical maximum value of 40 (5 EPEs or $5 \mathrm{ePEs}$ were selected in each of 8 clusters).

\subsection{Characteristics of events}

We investigated the extent and spatial distribution of extraordinarily high precipitation totals during the EPEs. It is evident from Fig. 5 that significant precipitation often hits areas larger than a cluster. That is particularly the case for the events in July 1981, August 1985, July 1997 and August 2002. On the contrary, there is no single event that significantly affected the entire Czech territory, despite its relatively small area $\left(78864 \mathrm{~km}^{2}\right)$. A few EPEs affecting only one cluster cannot be assumed as local events because they possibly also hit regions outside of the CR.

There are similar features among some events in terms of spatial distribution of precipitation. The second episode in 1954 and the events in 1981 and 1983 affected only the Bohemian clusters in western CR. At the beginning of July 1954, in August 1985 and in July 1997 precipitation fell over the Moravian and eastern Bohemian clusters. In May 1960, June 1968, July 1970 and in August 1972 heavy rains were recorded only within the eastern Moravian clusters. 


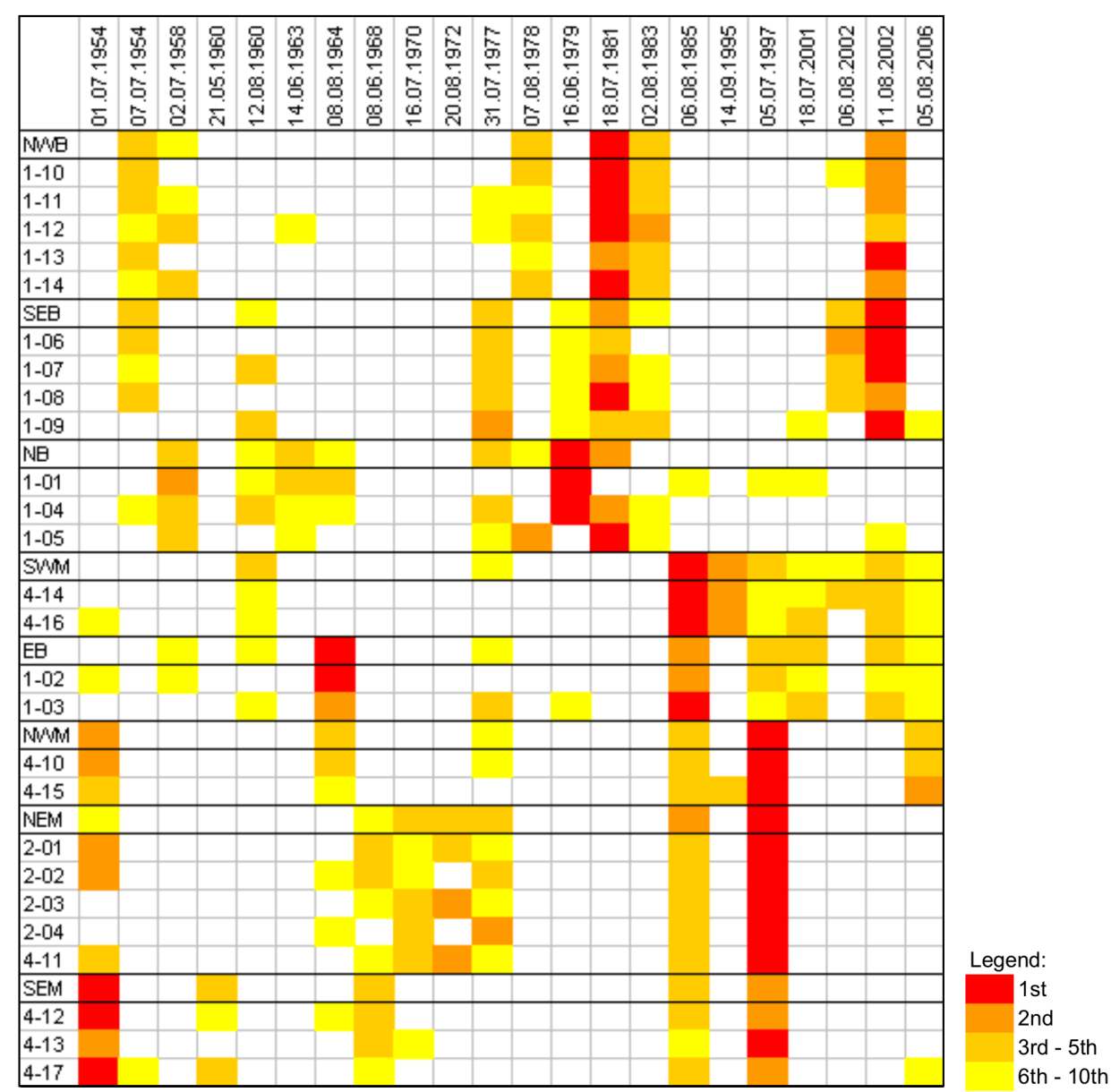

Fig. 5. The set of 22 cluster-related EPEs in the period of the warmer half-years from 1951 to 2006 . The first day of heavy rainfall is stated in the format dd.mm.yyyy. If the value of $R_{x}$ in a cluster (in a river basin) ranks among the ten historically highest values in that location, the cluster (the river basin) is highlighted by a colored box. The individual colors correspond to the ranking of the $R_{x}$ value according to the legend.

The event of July 1997 was unique in terms of precipitation totals. The absolute maximum of the criterion occurred in two clusters and in all respective river basins (Fig. 5). Figure 6 demonstrates that these maxima distinctly exceeded values of $R_{x}$ during other EPEs in these clusters. In fact, the maximum within the cluster, NEM, was substantially higher than the maxima of $R_{x}$ within all other clusters. The main reasons can be summarized as follows: (i) The northward decline of the orography makes the region highly exposed towards the flow of moist air within rearward cold sectors of thermally asymmetric cyclones, which is the typical circulation pattern inducing large-scale precipitation over Eastern Central Europe (Ustrnul and Czekierda, 2001). A cyclone, which is often of Mediterranean origin, mostly results from the wave of cold front connected with a steering North Atlantic cyclonic system (e.g., Rudari et al., 2004; Trigo et al., 2002). (ii) This synoptic pattern persisted for an uncommonly long period and was distinguished by extreme values of many thermodynamic characteristics, particularly the fluxes of moisture (Keil et al., 1999; Rezacova et al., 2005).

In July 1954 and August 2002, extraordinarily high precipitation totals occurred during two episodes that were separated by several days. This situation is dangerous from the hydrological point of view because precipitation during the first episode saturates the river basin so the response of the catchment is much more intensive during the second episode. In contrast to 1954 , heavy rainfalls affected almost the same area during both episodes in 2002 (Fig. 5). Moreover, the second episode was more significant than the first one (Fig. 5) and because of this, the situation in August 2002 produced comparatively catastrophic floods as it was in 1997.

\subsection{Seasonal and interannual variability of events}

In this work, we also focused on the analysis of temporal distribution of extraordinarily heavy rainfall events. Figure 7 


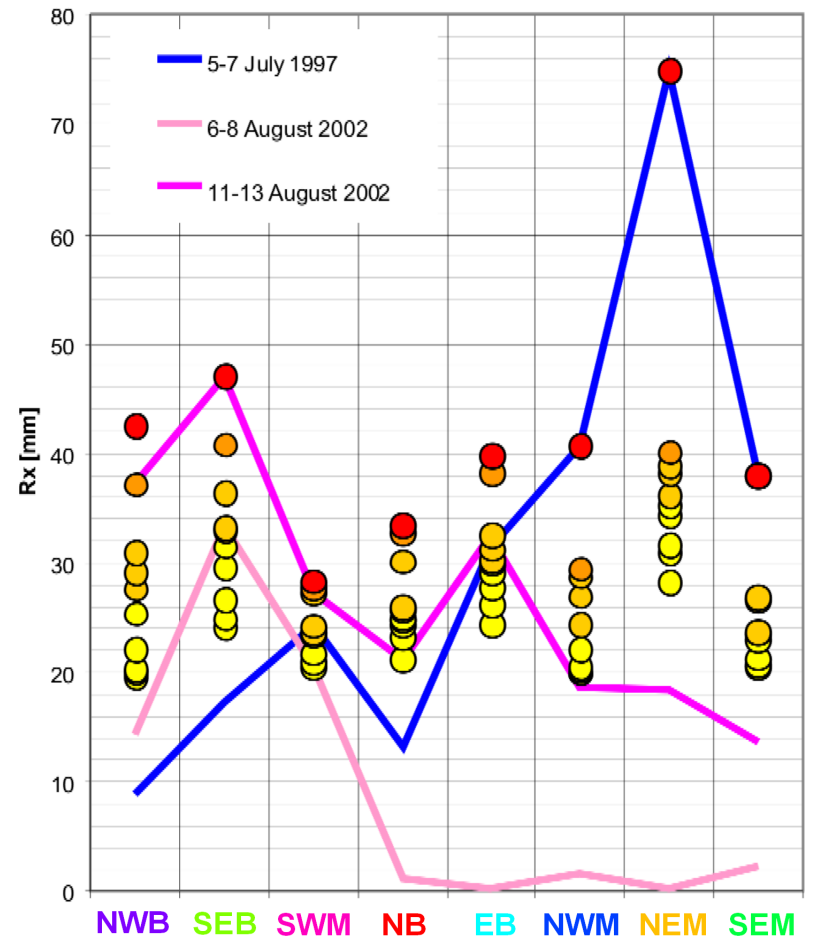

Fig. 6. Maxima of $R_{x}$ from 1951 to 2006 within the clusters of the river basins. The ten highest values representing the EPEs and the ePEs within each cluster are depicted by bubbles. The values of $R_{x}$ in July 1997 and in August 2002 are connected by lines.

schematically depicts the monthly distribution of the EPEs and ePEs and indicates the extremeness of the events within all eight clusters. The extremeness, $E$, was evaluated by the sum:

$E=\sum_{i=1}^{8} R_{x i} A_{i}$

where $i$ is the index of the cluster, $R_{x i}$ is the value of the criterion, $R_{\mathrm{x}}$, in the cluster, and $A_{i}$ is the area of the cluster. If $R_{x i}$ does not belong to the ten largest values of $R_{x}$ in the cluster, the value of $A_{i}$ is set to zero. The EPEs were concentrated in July and in the first half of August, which correspond to the climatologically determined maxima of air temperature and water vapor content in the CR (Tolasz et al., 2007). In addition, it is obvious from Fig. 5 that some clusters differentiated from the others. Primarily, the clusters, NEM and SEB, were affected by the EPEs, which all occurred exclusively from June to August. Since northern windward slopes of mountains are typical of both clusters, the orographic effects could dominate due to the high water vapor content during these months. Other months of the warmer half-years were characterized by weaker events with lower values of $R_{x}$. Such events from other clusters also affected the clusters, NEM and/or SEB, by comparable precipitation amounts, but they

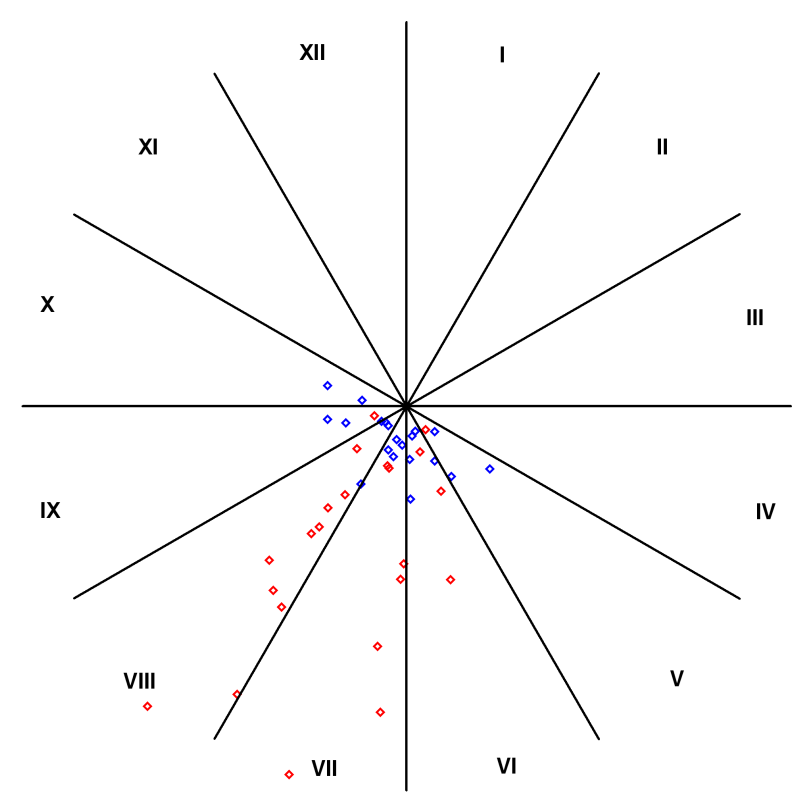

Fig. 7. Seasonality of exceptional precipitation events during the warmer half-years from 1951 to 2006. Red signs represent the EPEs and blue signs represent the ePEs. The distance of the sign from the center of the diagram is proportional to the extremeness of the event within the entire CR. The extremeness is evaluated by Eq. (4).

were much lower than the observed precipitation maxima in that location (Fig. 6).

The interannual variability of the EPEs can be discussed using Fig. 8. The steeper the steps, the more significant and/or more frequent the rainfall events that occurred during the years. It is evident that EPEs are not regularly distributed over the whole period from 1951 to 2006. In fact, the period seems to be divided into several segments with opposite characteristics. The years from the mid-1960s to the mid1970 s were characterized by a low frequency of EPEs. Only three events were detected and they affected exclusively the most eastern part of the CR. The following decade was more abundant in exceptional events. In contrast, no EPE occurred in the second half of the 1980s and the first half of the 1990s. The last decade of the studied period was again characterized by an increased frequency of EPEs that were rather weak, except the extremes in 1997 and 2002. Similar features can also be recognized when studying EPEs together with ePEs in Fig. 8. This indicates that the general characteristics of the interannual variability are relatively independent of the setting thresholds of the selection of events. The possible reasons for the outlined variability may be linked with longterm oscillations of the large-scale circulation. No significant trend in the frequency of the EPEs could be recognized. 


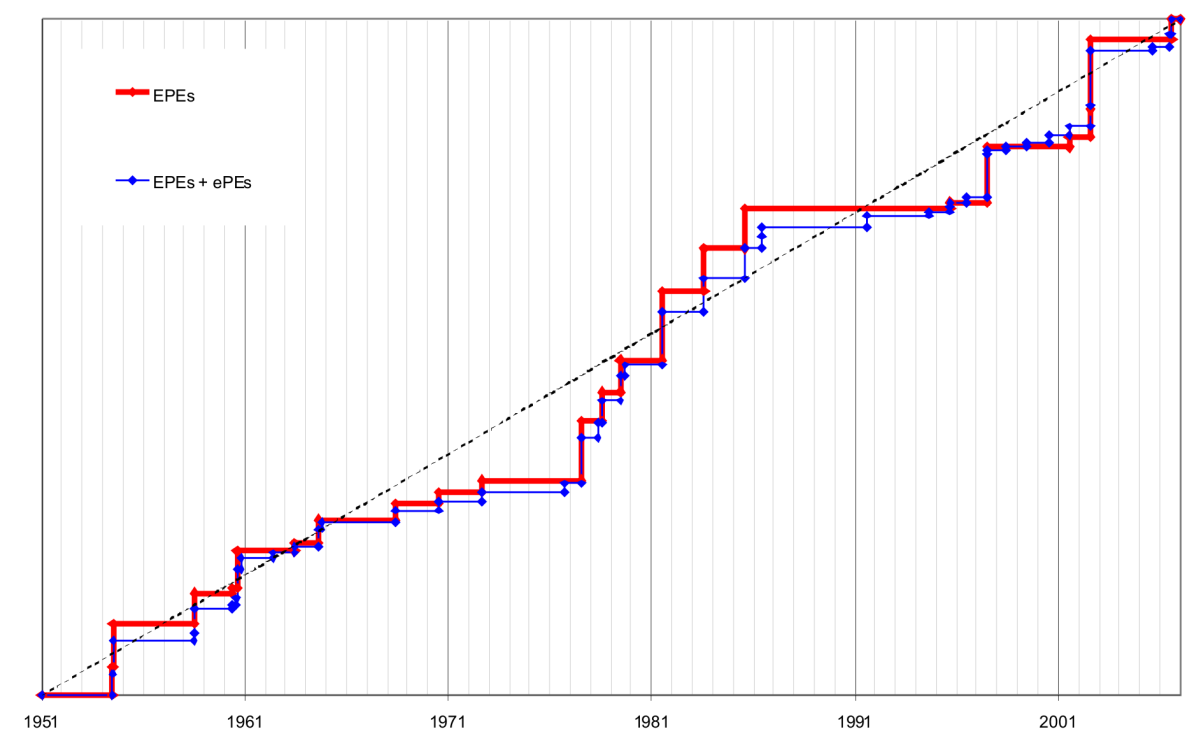

Fig. 8. Interannual distribution of the EPEs (red line) and the EPEs together with the ePEs (blue line) during the warmer half-years from 1951 to 2006. Vertical segments of the cumulative curves represent the events. The height of the segment corresponds to the extremeness of the event within the entire CR. The extremeness is evaluated by Eq. (4).

\section{Conclusions and outlook}

We proposed the criterion, $R_{x}$, as an indicator of the extremeness of large-scale rainfall events. The criterion assesses the extremeness of three-day precipitation amounts, taking into consideration the temporal distribution of daily precipitation totals within proper areas. In order to obtain such areas, we clustered the river basins with respect to their statistical similarities in high daily areal precipitation amounts. We defined eight clusters that mostly correspond to the main river basins.

Considering historic events with the five largest values of $R_{x}$ within each cluster, we defined a set of 22 extraordinarily heavy large-scale rainfall events. Furthermore, events with the 6th to the 10th largest values of $R_{x}$ were grouped together and comprised additional 20 events. During each of these 42 events, high precipitation totals were usually observed within an area larger than a single cluster. In addition, some events were characterized by similar spatial distribution of precipitation, which were probably related to similar circulation conditions in synoptic scale. The extreme events from July 1997 and August 2002 were unique in terms of precipitation totals; however, the event from August 2002 comprised two precipitation episodes. The occurrence of two episodes is not a rare feature, but the two episodes occurred in rapid succession and extraordinarily high precipitation totals affected almost the same area. The most significant events were concentrated in high summer, which was particularly typical of the orographically exposed SouthernBohemian and Northern-Moravian clusters. Considering the interannual variability, there are two main approximately tenyear periods with a low frequency of events (1965-1974 and
1986-1995) followed by a period with increased frequency. Although the two most extreme events occurred at the end of the studied period, no significant trend in the frequency could be recognized.

Regarding future activities, we will focus on the analysis of both the hydrological responses and the synoptic-dynamic conditions of the selected heavy large-scale rainfall events. We will define an alternative set of large-scale flood events using a purely hydrological criterion. Both sets will be compared and the possible disproportions will be interpreted by the spatio-temporal distribution of precipitation and/or the attributes of antecedent saturation within affected river basins. Furthermore, we will study the differences between the seasonal distribution of selected rainfall events and of floods. In order to analyze the synoptic-dynamic conditions before and during the selected rainfall events, we will employ synopticscale re-analyses. We will focus on the quantitative and objective classification of synoptic-scale conditions using the anomalies in (thermo) dynamic fields.

Acknowledgements. This contribution was prepared under the support of the projects GAAVCR KJB300420701 and KJB300420802 and the research program MSM 0021620831. Precipitation and runoff data were provided for research purposes by the Czech Hydrometeorological Institute.

Edited by: U. Ulbrich

Reviewed by: two anonymous referees 


\section{References}

Brazdil, R., Dobrovolny, P., Elleder, L., Kakos, V., Kotyza, O., Kveton, V., Mackova, J., Müller, M., Stekl, J., Tolasz, R., and Valasek, H.: Historical and Recent Floods in the Czech Republic, Masarykova univerzita Cesky Hydrometeorologicky Ustav, Brno and Prague, Czech Republic, 370 pp., 2005 (in Czech, including 83 pp. of an English abstract).

Campins, J., Genovesa, A., Jansa, A., Guijarro, J. A., and Ramis, C.: A catalogue and a classification of surface cyclones for the Western Mediterranean, Int. J. Climatol., 20, 969-984, 2000.

Conway, B. J., Gerard, L., Labrousse, J., Liljas, E., Senesi, S., Sunde, J., and Zwatz Meise, V.: Nowcasting. A survey of current knowledge, techniques and practice, EC, DG XII, Brusels, 501 pp., 1996.

Gong, X. and Richman, M. B.: On the application of cluster analysis to growing season precipitation data in North America east of the Rockies, J. Climate, 8, 897-931, 1995.

Grazzini, F. and van der Grijn, G.: Central European floods during summer 2002, ECMWF Newsletter, 96, 18-28, 2003.

Jansa, A., Genoves, A., and Garcia-Moya, J. A.: Western Mediterranean cyclones and heavy rain. Part 1: Numerical experiment concerning the Piedmont flood case, Meteorol. Appl., 7, 323 333, 2000.

Keil, C., Volkert, H., and Majewski, D.: The Oder flood in July 1997: Transport routes of precipitable water diagnosed with an operational forecast model, Geophys. Res. Lett., 26, 235-238, 1999.

Kundzewicz, Z. W., Szamalek, K., and Kowalczak, P.: The great flood of 1997 in Poland, Hydrol. Sci. J., 44, 855-870, 1999.

Martin, M. L., Santos-Munoz, D., Morata, A., Luna, M. Y., and Valero, F.: An objectively selected case study of a heavy rain event in the Mediterranean Basin: A diagnosis using numerical simulation, Atmos. Res., 81, 187-205, 2006.

Matejka, T. J., Houze Jr., R. A., and Hobbs, P. V.: Microphysics and dynamics of clouds associated with mesoscale rainbands in extratropical cyclones, Quart. J. Roy. Meteor. Soc., 106, 29-56, 1980.

Mudelsee, M., Börngen, M., Tetzlaff G., and Grünewald, U.: Extreme floods in central Europe over the past 500 years: Role of cyclone pathway "Zugstrasse Vb", J. Geophys. Res., 109, D23101, doi:10.1029/2004JD005034, 2004.

Naber, G. L.: The Geometry of Minkowski Spacetime, SpringerVerlag, New York, 1992.

Niedzwiedz, T.: Rainfall characteristics in Southern Poland during the severe flooding event of July 1997, Studia Geomorphologica Carpatho-Balcanica, 33, 5-25, 1999.
Porcú, F., Caracciolo, C., and Prodi, F.: Cloud systems leading to flood events in Europe: an overview and classification, Meteor. Appl., 10, 217-227, 2003.

Rezacova, D., Kaspar, M., Müller, M., Sokol, Z., Kakos, V., Hanslian, H., and Pesice, P.: A comparison of flood precipitation in August 2002 with historical extreme precipitation events from the Czech territory, Atmos. Res., 77, 354-366, 2005.

Roberts, N. and Young, M.: Questionnaire on the operational value of conceptual models, in: COST78 Improvement of nowcasting techniques, Final report, edited by: Lagouvardos, K., Liljas, E., Conway, B., and Sunde, J. EUR., 251-270, 2001.

Rudari, R., Entekhabi, D., and Roth, G.: Terrain and MultipleScale Interactions as Factors in Generating Extreme Precipitation Events, J. Hydrometeorol., 5, 390-404, 2004.

Smith, K. and Ward, R.: Floods - physical processes and human impacts, John Wiley \& Sons Ltd, Chichester, 382 pp., 1998.

Sokol, Z.: The use of radar and gauge measurements to estimate areal precipitation for several Czech river basins, Stud. Geophys. Geod., 47, 587-604, 2003.

Sopko, F.: Model predictions of the floods in the Czech Republic during August 2002: the forecasters' perspective, ECMWF Newsletter, 97, 2-6, 2003.

Tolasz, R., Mikova, T., Valerianova, A., et al.: Climate Atlas of Czechia. Cesky Hydrometeorologicky Ustav and Univerzita Palackeho, Prague and Olomouc, Czech Republic, 256 pp., 2007.

Trigo, I. F., Bigg, G. R., and Davies, T. D.: A climatology of cyclogenesis mechanisms in the Mediterranean, Mon. Weather Rev., 130, 549-569, 2002.

Ulbrich, U., Brücher, T., Fink, A. H., Leckebusch, G. C., Krüger A., and Pinto, J. G.: The central European floods of August 2002 - Part 1: Rainfall periods and flood development, Weather, 58, 371-377, 2003a.

Ulbrich, U., Brücher, T., Fink, A. H., Leckebusch, G. C., Krüger, A., and Pinto, J. G.: The central European floods of August 2002 - Part 2: Synoptic causes and considerations with respect to climatic change, Weather, 58, 434-442, 2003b

Ustrnul, Z. and Czekierda, D.: Circulation background of the atmospheric precipitation in Central Europe (based on the Polish example), Meteorol. Z., 10, 103-111, 2001.

Ward, J. H.: Hierarchical grouping to optimize an objective function, J. Amer. Stat. Assoc., 58, 236-244, 1963.

Wibig, J.: Precipitation in Europe in relation to circulation patterns at the $500 \mathrm{hPa}$ level, Int. J. Climatol., 19, 253-269, 1999.

Zängl , G.: Numerical simulations of the 12-13 August 2002 flooding event in eastern Germany, Quart. J. Roy. Meteor. Soc., 130, 1921-1940, 2004 